\title{
Requirements Engineering Education in the 21st Century, an Experiential Learning Approach
}

\author{
Gil Regev ${ }^{1}$, Donald C. Gause ${ }^{2}$, Alain Wegmann ${ }^{1}$ \\ ${ }^{1}$ Ecole Polytechnique Fédérale de Lausanne (EPFL), School of Computer and Communication \\ Sciences, CH-1015 Lausanne, Switzerland, \{gil.regev, alain.wegmann\}@epfl.ch \\ ${ }^{2}$ State University of New York at Binghamton and Savile Row, LLC, U.S.A \\ dgause@binghamton.edu
}

\begin{abstract}
RE use in industry is hampered by a poor understanding of RE practices and their benefits. Teaching RE at the university level is therefore an important endeavor. This education can ideally be provided at the university level as an integrated part of developing the requisite $R E$ and software engineering technical skills, shortly before students become engineers and enter the workforce. However, much social wisdom is packed into RE methods. It is unrealistic to expect students with little organizational experience to understand this body of knowledge.

The course described in this paper uses an active, affective, experiential pedagogy giving students the opportunity of experiencing a simulated work environment that demonstrates the social/designproblem complexities and richness of a development organization in the throws of creating a new product.

Emotional and technical debriefing is conducted after each meaningful experience so that students and faculty, alike, can better understand the professional relevancies of what they have just experienced. This includes an examination of the many forces experienced in industrial settings but not normally discussed in academic settings. The course uses a lowtech social simulation rather than software simulation so that students learn through interaction with real people and therefore are confronted with the complexity of true social relationships.
\end{abstract}

\section{Introduction}

RE use in industry is hampered by a poor understanding of RE practices and their benefits. RE education is therefore an important endeavor that can improve the adoption of RE methods in businesses. Ideally this education needs to be provided at the university level, before students become engineers and enter the workforce. Unfortunately, most computer science and software engineering programs do not include RE courses [1]. When they do, these courses are often given in the traditional lecture/exercise format. Few publications, e.g. [5, 6, 11] report on other types of pedagogy used to teach RE.

Requirements represent the expression of people's desires [7]. To understand and express the desires of people is essentially a social construction. Hence, much social wisdom is packed into RE methods. It is unrealistic to expect students with little organizational experience to understand this body of knowledge and to appreciate even the need for RE methods, much less to be able to use them. It is essential that software engineering students understand the latest, accepted methods and practices in use today in the design of complex computing systems. This, alone, is not enough, however. This knowledge is, of course, required as a professional entry point. If we want to provide more than a shallow understanding of RE to students, we need to provide them with more than just lectures about RE methods and academic problems where they can exercise the knowledge (or rather the information) they have been provided in our traditional didactic teaching environment. Ideally, it would be good to already have had some, or currently be having, business experience as a prerequisite or co-requisite to an RE course.

As an illustration, following is an excerpt from a Q\&A with Barry Boehm [4]:

\footnotetext{
“What advice would you give to all the 'youngsters' who are just starting out in software engineering [information systems development] ${ }^{\mathrm{i}}$ research?”

"Spend some time in industry working on real software development [information systems development] projects. You need to get your hands dirty and learn not in your mind but in your heart and gut the problems that real software engineering [and information systems development] faces. This will help you understand what research ideas you have that might be most applicable in practice."
}

In practice, it requires a curriculum in which students do internships in the middle of their studies. However, even this is no guarantee that they will be exposed to the experiences that they will need to more fully appreciate and understand an RE course. 
The experiences we seek to impart to students are directly linked to the issues found in the workplace when we understand what the business is about and what the desires of people are. A short list of these issues is: dealing with ambiguity, uncertainty, confusion, fear, time pressure, collaboration, corporate politics etc. In sum, what some call the "messy" part of organizations [3]. The messy part, recognized by scientists and mathematicians as wicked problems, exemplify the differences between classroom and workplace problems.

To manage this messy part, it is necessary to bring to bear both techniques and emotions - the heart and gut referred to by Barry Boehm. Whereas the use of specific techniques and algorithms can be learned through lectures and exercises, emotions can only be learned through real life experiences.

This paper describes the requirements engineering part of an experiential Enterprise Architecture (EA) course delivered at the Ecole Polytechnique Fédérale de Lausanne (EPFL), Switzerland. We explain the reasons we created this course, its essential pedagogical features and the way they were delivered, and the experiences we had giving it. The course was given from 1997 through 2000 as an information systems course with an experiential pedagogy [14]. The case study used in the course and the technical part were overhauled. The course was renamed Enterprise and Service Oriented Architecture (ESOA), and given again in 2007 [16] and 2008. We mainly describe our experience with the 2007 version of the course with some elements from 2008.

The course was the result of a major effort by a teaching team including a professor, four teaching assistants and a visiting professor. Several members of the team have many years of experience in the IT industry. The course reflects their collective experience. It was therefore designed to create a realistic organization in order to provide the students an opportunity to experience the "messiness" they can expect in the workplace. We recreated situations similar to those they themselves faced in their business careers. We framed the problems given to the students in an uncertain and confusing reality, often relying only on verbal, word-of-mouth communication as this is an important part of design and management information transfer in reality.

The approach we took with this course included an immersion in a more realistic social environment, with tools that emulate those used in industry rather than a computer simulation. The students interview real people rather than simulated people and use an actual tiny Material Resource Planning (MRP) system rather than a simulation. The active experimentation is followed by the debriefing of emotional and technical issues as they occur.

In Section 2 of this paper we describe the nature of $\mathrm{RE}$ education related problems. In Section 3 we present the basics of experiential learning. In Section 4 we explain the use of experiential learning in the 2007 version of the ESOA course. In Section 5 we explore our own experience with the course, including examples of student evaluation. In Section 6 we outline the related work before summarizing our contributions and delineating the future work we envision.

\section{The Nature of RE Problems}

It has been known for many years that the curriculum in traditional education is partitioned into separate disciplines. Few, if any, courses seek to integrate disciplines. Going through the system, students acquire much factual knowledge about specific areas but little synthesis is provided.

A slight exaggeration, if any, of a traditional means of teaching college students involves instructors opening the class with Topic A, spending however much time is required through lectures to impart Topic A, assigning homework over this period and following up with an examination of Topic A. The examination problems draw, almost entirely, on the methods introduced in Topic A. The examination is graded and returned to the student. The teacher closes the file on Topic A and moves on to Topic B. This process continues through the remaining topics until the end of the semester. We, as university teachers are unwittingly creating a student mindset that partitions out methodologies. The course is partitioned into a sequential set of several topics with the implication that there is little, if any, relationship between these topics and even less of a relationship between courses. We discovered, while deliberately trying to stretch students' thinking in the capstone class, that students have a difficult time integrating topics and course materials across the topic and course boundaries unless we make extra effort to develop assignments that require this integration in order to successfully complete their assigned projects.

Furthermore, the nature of classroom problems is quite different from those experienced in the workplace. Table 1 summarizes the differences that we feel are critical between classroom and work problems. Classroom problems are well defined. They have predefined solutions, known by the professor, they relate to recent material taught in class and their definitions do not change while they are being resolved. 


\begin{tabular}{|c|c|c|}
\hline Experience & Classroom & Workplace \\
\hline $\begin{array}{ll}\text { 1. } & \text { Problem } \\
& \text { definition }\end{array}$ & Well defined. & $\begin{array}{l}\text { Ill-defined. Half of the challenge is just defining } \\
\text { the problem. Often, in fact, a solution is implied by } \\
\text { a mutually acceptable definition. }\end{array}$ \\
\hline $\begin{array}{ll}2 . & \text { Problem } \\
\text { approach }\end{array}$ & $\begin{array}{l}\text { Strongly indicated by most recently } \\
\text { presented classroom material. Problems } \\
\text { tend to be carefully compartmentalized to } \\
\text { reinforce specific methodologies. }\end{array}$ & $\begin{array}{l}\text { Few hints as to how to approach the problem. In } \\
\text { small companies, there will likely be no one to go } \\
\text { to for help. You will, nearly always, be required to } \\
\text { go beyond past studies and methods and may be } \\
\text { required to invent new methods. }\end{array}$ \\
\hline $\begin{array}{ll}\text { 3. } & \text { Problem } \\
& \text { solutions }\end{array}$ & $\begin{array}{l}\text { Professor always knows the solution. If } \\
\text { the problem is an odd numbered problem, } \\
\text { the solution is in the back of the book. }\end{array}$ & $\begin{array}{l}\text { A solution to the problem will only be apparent } \\
\text { when it has been accepted by management. }\end{array}$ \\
\hline 4. $\quad$ Problem scope & $\begin{array}{l}\text { Many problems are "scoped" so that they } \\
\text { can be solved by one person (student) in a } \\
\text { few days or weeks. }\end{array}$ & $\begin{array}{l}\text { The scope of the problem will not be recognized } \\
\text { and you will be expected to produce the resources } \\
\text { and time necessary to achieve the end result. In } \\
\text { general, problems require a team of several people } \\
\text { working over a period of many months. }\end{array}$ \\
\hline $\begin{array}{ll}5 . & \begin{array}{l}\text { Social } \\
\text { environment }\end{array}\end{array}$ & $\begin{array}{l}\text { Working as an individual with implied } \\
\text { competition. }\end{array}$ & $\begin{array}{l}\text { Working as a team member, cooperation being } \\
\text { essential. }\end{array}$ \\
\hline $\begin{array}{ll}6 . & \text { Information } \\
& \text { levels }\end{array}$ & Accurate, well defined, explicitly stated. & $\begin{array}{l}\text { Vague, unrecognizably ambiguous. Occasional } \\
\text { hidden agendas. Credibility of the source and } \\
\text { timeliness of the information is always an issue. }\end{array}$ \\
\hline $\begin{array}{r}\text { Solution } \\
\text { methods }\end{array}$ & $\begin{array}{l}\text { Given by an authority figure, usually to } \\
\text { reinforce material recently presented. } \\
\text { Veracity and efficacy never an issue. }\end{array}$ & $\begin{array}{l}\text { May have to invent a new method as part of the } \\
\text { problem solving process. Authority figure often } \\
\text { projects his/her solution as the method of approach. }\end{array}$ \\
\hline $\begin{array}{ll}8 . & \text { Design team }\end{array}$ & $\begin{array}{l}\text { Same group of members from beginning to } \\
\text { end of project (14 weeks). }\end{array}$ & $\begin{array}{l}\text { New members join the team and old, experienced } \\
\text { members leave the team, sometimes at the worst } \\
\text { possible times. }\end{array}$ \\
\hline $\begin{array}{l}\text { 9. Stability of } \\
\text { problem } \\
\text { statement }\end{array}$ & $\begin{array}{l}\text { Once stated, the problem statement is } \\
\text { rarely, if ever changed. }\end{array}$ & $\begin{array}{l}\text { The problem statement changes frequently as new } \\
\text { information becomes available and new clients are } \\
\text { brought into the picture`. }\end{array}$ \\
\hline $\begin{array}{l}\text { 10. Information } \\
\text { channels }\end{array}$ & $\begin{array}{l}\text { Heavy use of well-documented, written } \\
\text { form. }\end{array}$ & $\begin{array}{l}\text { Some documentation but much critical information } \\
\text { is conveyed in "expedient" verbal (sometimes, off- } \\
\text { hand) forms such as one-on-one meetings, } \\
\text { telephone and other informal conversations. }\end{array}$ \\
\hline 11. Conflict & $\begin{array}{l}\text { Conflict with authorities is strongly } \\
\text { discouraged. Conflict with colleagues is } \\
\text { best ignored as it will go away in } 15 \\
\text { weeks. }\end{array}$ & $\begin{array}{l}\text { Conflict with authorities is strongly discouraged. } \\
\text { Conflict with colleagues is best ignored as it will go } \\
\text { away by project end. }\end{array}$ \\
\hline
\end{tabular}

Table 1: The difference between classroom and workplace problems [8]

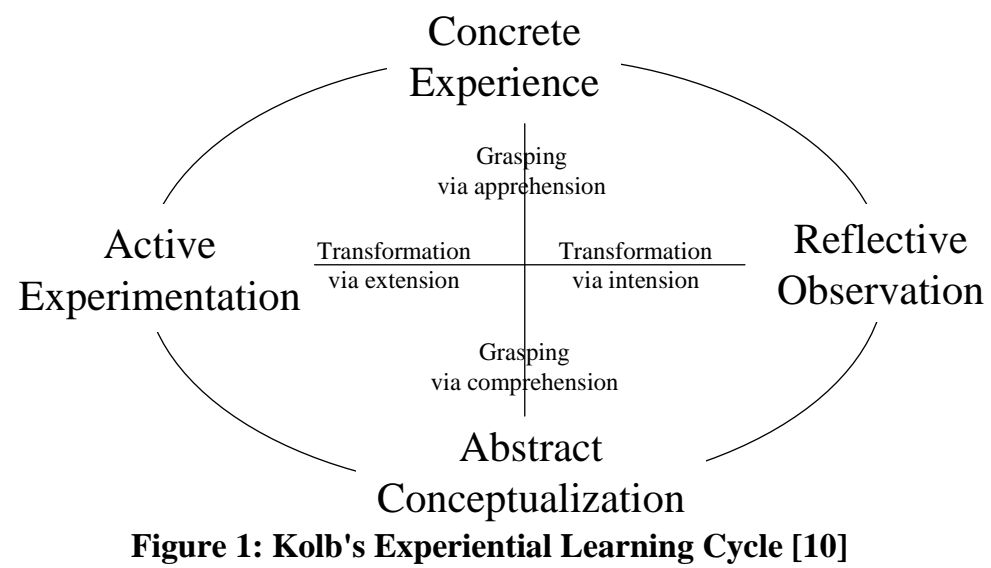


Conversely, wicked problems are often not well defined. The definition, if given at all, changes over time. Their solution is not known at the beginning and whether they were correctly solved will not be known often until long after a solution was proposed. Solving a workplace problem often brings about a host of other problems that could not be foreseen before the solution was implemented - the famous or infamous unintended consequences of each new product entering the marketplace for the first time.

Item 11 of Table 1, i.e. conflict, is remarkable in that the treatment of the problem is almost identical in the workplace and in the student situation. This points to one of our shortcomings in RE education and research alike. We, as engineers, have a tendency to ignore conflict rather than recognize the source of the conflict and use it to learn more about the design problem. Although we recognize the several major sources of conflict, such as organizational, attitudinal, diversity of individual experiences and world views, one source we do not readily recognize is ambiguity in the requirements. We claim that conflict in the early stages is proper and even advantageous when managed properly. Getting to the bottom of such conflicts often pays dividends in surfacing design issues and assumptions that would likely go unrecognized. In these cases, the conflict moves from human conflict to product conflict as each member of the design team makes design decisions they prefer, for whatever reason, and the final product will exhibit each of the implicitly conflicting viewpoints. We believe that the $\mathrm{RE}$ profession and educators need to see conflict as attorneys see it, as a means to getting to the truth of a situation. Attorneys learn to be objective about conflict and, in fact to argue each side of an issue.

Workplace problems are often referred to as ill defined or wicked problems. Wicked Problems have the following properties [13]:

- cannot be easily defined so that all stakeholders agree on the problem to solve;

- $\quad$ have no clear stopping rules;

- have better or worse solutions, not right and wrong ones;

- $\quad$ have no objective measure of success;

- require iteration--every trial counts;

- $\quad$ have no given alternative solutions--they must be discovered;

- require complex judgments about the level of abstraction at which to define the problem;

- often have strong moral, political or professional dimensions which cannot be easily formalized.

Requirements Engineering can be considered as a meta-discipline, in that it integrates a number of other disciplines e.g. organizational theory, psychology, sociology, software engineering, ethics. Indeed, RE is a discipline that was created in order to discover people's desires [7]. Discovering people's desires is fundamentally a messy, wicked problem.

In our experience, students who have been only trained in the academic curriculum and do not have an industrial background are very often impervious to RE issues. They fail to see the point in spending much time to understand the business requirements. If they are at all sensitive to the question of requirements, they usually believe that it is enough to ask the stakeholders what they want, write it down, and obtain a sign-off. If they have not been exposed to the requirements subject, even the process above is a discovery.

For example, in wicked problems, every trial counts, so it is not possible or advisable to give students the rules of business. They have to live through the problems. However, many students are resistant to this pedagogy and want to receive all the relevant theory and rules so that they can efficiently solve the problem given by the teacher. Also, often students are relatively passive, awaiting the lecturer to deliver the required knowledge to them.

Furthermore, students are unaware of creativity techniques and the need to use them for defining requirements: such techniques as metaphorical and analogical thinking, brainstorming, idea sketching and many other approaches commonly used in other, more mature areas of engineering design.

RE courses usually teach students how to define requirements that are complete and rigorous. This may give students the impression that stakeholders know what they want or at least are able to clearly express their problems when interviewed or surveyed. In our experience, this is often not the case in organizations. No one stakeholder constituency can possibly know what they want or imagine the full set of opportunities the next system can implement without consultation with many other stakeholder constituencies.

\section{Experiential Learning}

The theory of experiential learning is generally attributed to Kolb [10]. Kolb developed this theory as a way to evolve beyond traditional classroom teaching techniques that favor detached learning of abstract concepts disconnected from direct experience. Experiential learning has its roots in the pioneering work of educators such as Dewey, Lewin, Piaget, and Freire. Much of Kolb's arguments in favor of experiential learning sound modern, even though they date from the early 1980s and are built on work that began in the $19^{\text {th }}$ century by Dewey. 
Hence, according to Kolb, Dewey's ideas were developed to "meet the challenges of coping with change and lifelong learning." And experiential learning is receiving renewed interest, among other things, because of "employers who feel that the graduates they recruit into their organizations are woefully unprepared.” [10].

Experiential learning as described by Kolb promotes the idea that experience is at the root of learning and its corollary, intelligence. Experience is seen as an interaction or more as a, transaction between a person and her environment. Abstract thinking is a product of concrete experience rather than knowledge that can be learned from books and lectures.

Kolb integrated the theories of Dewey, Lewin, Piaget, and Freire into four modes of experiential learning. Learning occurs through the confrontation of these four modes. The fours modes, usually assembled in what is called the experiential learning cycle (Figure 1) are Concrete Experience (CE), Reflective Observation (RO), Abstract Conceptualization (AC), and Active Experimentation (AE).

In Kolb's own words [10], learners "must be able to involve themselves fully, openly, and without bias in new experiences (CE). They must be able to reflect on and observe their experiences from many perspectives (RO). They must be able to create concepts that integrate their observations into logically sound theories (AC), and they must be able to use these theories to make decisions and solve problems (AE).”

Kolb notes that this cycle is an ideal that is difficult to achieve because learners cannot easily reconcile these modes, which require different ways of interacting with one's environment and thinking about it. He further notes that these modes are "dialectically" opposed along two dimensions. The first dimension, called prehension, opposes Concrete Experience of events (apprehension) and Abstract Conceptualization that seeks to make generalizations of these events (comprehension). The second dimension, called transformation, opposes Reflective Observation about experience (intension) and Active Experimentation that seeks to make decisions about future experience (extension). For Kolb, the level of learning is determined by the way the learner can resolve the conflicts present in these two dimensions.

Another aspect that enhances learning was described by Vygotsky as the zone of proximal development. For children, the definition of the zone of proximal development is: "the distance between the actual developmental level as determined by independent problem solving and the level of potential development as determined through problem solving under adult guidance or in collaboration with more capable peers [10]. However, in our case it may be extended to RE students as what they can learn with the help of a teaching team with RE and industry experience.

As we have seen in the previous section, workplace and wicked problems require an iterative process for their resolution. During this process, the problem itself, which is ill defined to begin with, gradually becomes clearer, hopefully. Just as hopefully, students comprehend the nature of RE and business problems through their apprehension of the concrete classroom experience.

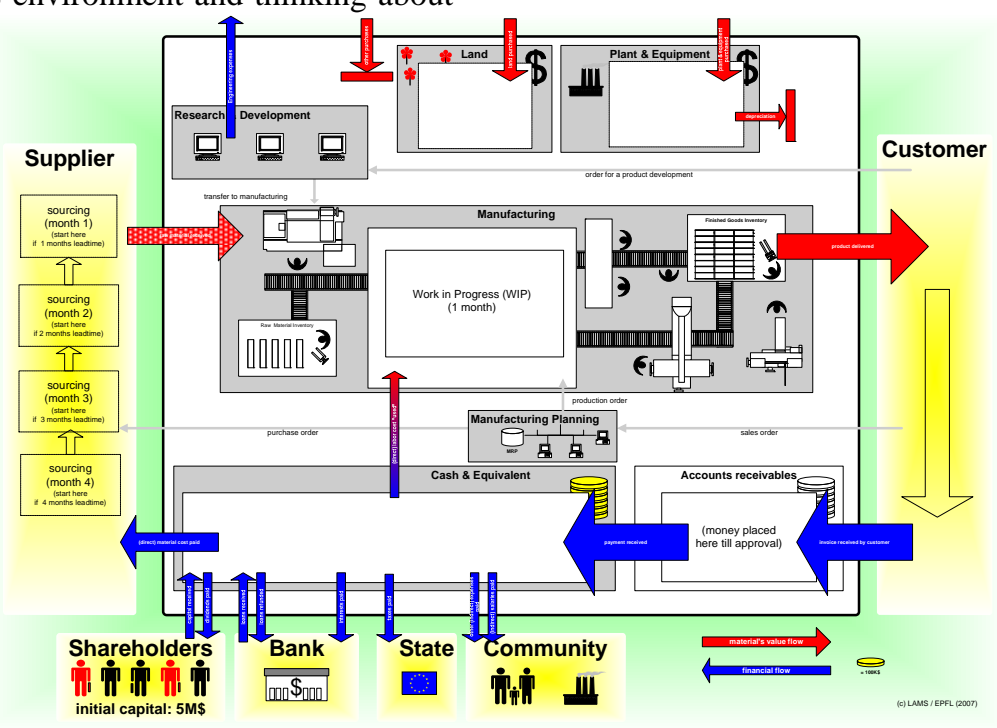

Figure 2: Business game board 


\section{The ESOA Course}

The ESOA course $[14,16]$ was designed so that it follows the experiential learning cycle. In a typical course session of three periods of forty five minutes each, the students were first "plunged" into a simulated real world experience that can be either a business game or an RE style interview session or a software development task. These experiences lasted for 2 periods (roughly ninety minutes). Most experience sessions were followed by a reflective observation phase, a 45 minute period of emotional and technical debriefing. In the emotional part, the students had the opportunity to express their frustration with the experience they had just gone through. In the technical debrief, they reflected on the techniques that can be used to solve the problems they faced. Most debriefings were followed by a lecture, usually in the next first period of the following session. The lecture presented the theory related to the problems and techniques identified during the debriefing sessions. Aspects of contextual interviews were presented after a first session of standard interviews failed to provide a complete picture of the design or process problem to be solved.

The RE phase of the course is at the interface between the business understanding and the product or service to be created The students first need to understand how the business functions and only later can they embark on the RE process, conducting interviews, drafting requirements etc. The course was therefore partitioned into 3 modules.

1. Business game

2. Requirements Engineering and specifications

3. Implementation

In the business game the students were asked to form teams; each team was considered as a separate company. The companies were to compete within a same market segment for acquiring the business of a client company. The student companies were given identical seed money, a corporate identity and a mission. The mission is to design, manufacture, sell and maintain light airplane diesel engines. At the beginning of the game each student company was given a Request For Quotation (RFQ) supposedly issued by the client company (an airplane manufacturer). The only information given to each team was a game board (Figure 2), background information about the RFQ process, a catalog of engine part manufacturers listing existing engine designs and their associated parts, a J2EE application that mimics a 1980s style Material Resource Planning (MRP) system (including tracking of the RFQ process, company financials, order tracking etc.). During the first four weeks of the course, each team had to experience and understand the following issues:

- the RFQ process,

- how to answer the RFQ

- how to decide on buy vs. make

- $\quad$ how to plan manufacturing

- defect and rework management

- quality management

- company financials

The students were placed under extreme time pressure, instructed to respond to the RFQ in the timeframe of 2 course periods (90 minutes). Every 5 minutes, a bell rang to announce the passing of a fiscal month. Each month, the MRP system would deduct employee salaries and other fixed charges from the company's bank account, creating additional stress. To respond to the RFQ, each team had to select a supplier of parts for their engine, which required a selection of an engine design and a buy vs. make decision. This fixed the cost of an engine and the delay to design a solution and to manufacture an engine. This information was needed to respond to the RFQ.

As a result of the severe time pressure, each student team struggled to understand the background documentation, catalog, game and MRP. We observed that in most cases the game board and background documentation were neglected, so that in most teams there was no overall picture of what was going on. Basic emotions such as frustration and anger surfaced quite rapidly among the students. Several of the complaints expressed doubts about the competence of the teaching team.

The first module was followed by a 7 week module devoted to requirements engineering and specifications. In the first week of the module, the students were given a short statement of a sales problem their company was facing, and instructed to complete a simplified Software Requirements Specifications (SRS) for a system that will solve the problem. They were told that they could obtain more information about the problem by interviewing several internal stakeholders (CEO, CTO, employee), as well as two outside stakeholders (a customer and an airplane mechanic). A play script containing the main message to be conveyed during the interview was prepared for each interviewee. Only the main message was detailed so that the interviewees could speak freely without forgetting to say the important aspects of their role. There was only one interview session for each interviewee so the students had to split up the company teams they had formed in the first four weeks and formed functional groups that will interviewed each stakeholder. 


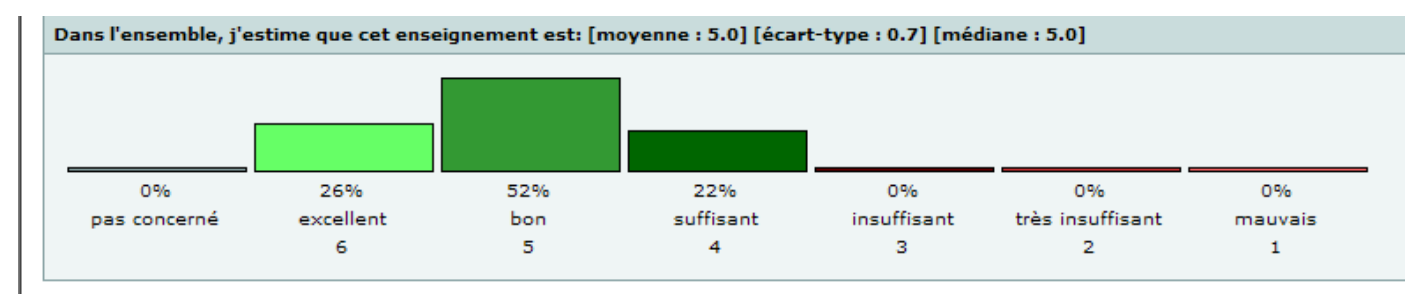

Figure 3: Course Evaluation

After these interviews were conducted, each team wrote its own SRS which they had to present to the company's main investor for approval. Of course, the SRS was not to the liking of the investor who asked to have more information about the feasibility and validity of their proposed solution. To satisfy these demands, the students found out that they needed to do more interviews, most notably by conducting contextual interviews [2] with existing stakeholders and an interview with a customer who would not buy their products, Mr. Skeptical. They also had to come to grips with the emotions resulting from the rejection they experienced from their main investor.

In this second round of interviews, the students learned that their understanding of the problem was too partial and that they needed much more analysis to understand what the problem was and what would qualify as a good solution. They then spent 5 weeks modeling the enterprise with our SEAM Enterprise Architecture (EA) method [15]. The last three weeks of the course were devoted to actually prototyping the system described in the SRS and the enterprise models with a Business Process Management (BPM) tool. Subsequently, each team had to rewrite the SRS and submit an executive summary including features such as Return On Investment (ROI) in a language understandable to a non-technical investor.

\section{Experience with the Course}

The course was given to approximately 40 students (out of a total of about 100 eligible students). This is considered to be very large attendance for an elective course. It should be noted that the students voluntarily selected the course with no coaxing or other instructor influence. The 2007 version of the course was well evaluated (see Figure 3) with $78 \%$ of the students rating the course as excellent or good (this has dropped in 2008 with only 57\% rating it excellent or good.). We have noticed the following areas for improvement.

\section{Acceptance of the Experiential Learning Style}

The course is immersive and problem-based. It was very important to explain frequently why the course was so different from the other courses (at least in the first and second weeks and at the beginning of each section). The two comments below illustrate that for some (most) students the course structure was understood.

\begin{abstract}
"The course is very well structured, many new concepts are presented, but easy to understand and learn due to the fact that we are directly placed in a situation before we learn the theory. We discover the different problems encountered by ourselves and then the theory enables to consolidate the knowledge learned during the experimentation.”

"The class material is very interesting, but often we don't have enough theory to do the exercises and we spend too much time not knowing what to do and asking questions. It would have been much better to have theory part with all information, then clear task description and finally 10minutes (measured in a Swiss way) to do what we have to do. Apart from this the class is very interesting and the material presented is useful."
\end{abstract}

However, until the last day, a few students did not accept this style of learning, saying that the course was disorganized and that they preferred lectures followed by clearly described exercises. It is surprising that they remained in the course despite this.

A few students complained about the class-level debriefing being boring (as most groups had similar findings). This problem could be alleviated by not asking the student teams to present their learning individually but to have the professor make a synthesis of each of their comments. However, this will reduce the active participation of the shyest students.

At the beginning of the course, we made sure the students understood that their performance during the course will not affect their grade. The grade was only the result of their performance during the final oral exam. Our intent was to enable them to live fully through the experiences of the course without being afraid of being judged so as to maximize learning and risk taking.

\section{Knowledge Transfer}

The exam was an oral in which the students had to solve a new problem, answer a theoretical question and explain a detail (picked by the professor) on their model. The results were good (4.9 out of 6). We also made a correlation between the student grade and the 
student participation in the class. As the work was done in groups, quite often the work was executed by one or two students - with the others watching. Our statistics show that the students who took the course passively received, on average, one point less. It was also surprising to see that some of the very advanced students (who run a business in parallel) got very low grades - even with a regular participation in the course. Our hypothesis is that they knew that they were good developers and they did not have the openness to question themselves.

It was also important to explain in the course, on multiple occasions, how the exam would be structured. This was essential to allow students to know what to learn and to help them feel more confident.

Some of the students who took the course make their master's project in industry under our supervision. We noticed that they do not always notice that the knowledge gained in the course can be used in their master's project. Our main coaching activity is to work with them on realizing this and to promote the reuse of the knowledge. This is an area that needs to be further improved.

\section{Credibility}

One of the extremely important aspects of the course is its credibility. As the course puts the student in a stressful situation, the student might infer that the course is disorganized. With adequate communication, the students eventually believe that the course puts them in a situation related to the "real life" situation and learn from their experience.

During the first sessions of the course, we were repeatedly challenged by the more skeptical students as to its handling of the course and its business expertise. The challenge was expressed by comments during the experimentation and as open criticism during some the emotional debriefing sessions.

Our participating visiting professor presented a lecture dealing with the differences between industry and academia, citing professional society surveys, leading engineering educators and executives consistent with, and summarized by Table 1 . He was also careful to give the industrial backgrounds of the instructors in meetings with student teams whenever appropriate.

We did the following to raise the course credibility:

- We were not shy in describing our accumulated industrial experience

- We invited five guest speakers (4 industry practitioners and one professor) who presented real projects (one in each module of the course and two for the overall course). Even without prior briefing of the speakers, their presentations were close enough to the material taught in the course for the students to believe in what they experienced.

- The professor and the four TAs were heavily involved in the entire course. The students reacted very positively to this full involvement.

However, we were not really prepared for the students' doubts in our abilities and the handling of conflict is one of the areas that need improvement.

\section{Emotional Relations}

The debriefing sessions addressed both emotions and technical knowledge. For example, in the first sessions, the students learned to manage stress by becoming specialized in different roles, thereby learning to better work together. In the debriefing sessions we discussed the difficulties they had to assume these specialized roles. Some of these difficulties stem from the fact that some students do not attend all sessions of the courses (because they are free to attend or not), it is difficult for the team to assume this specialization. Hence, if a student assumes the role of CFO of the company and this student misses a class, the company has no more financials. This also points to the tension between specialization and generalization [17]. In the related theory sessions we explained some of these tensions. .It is an aspect we will address more in the future versions of the course.

The course does not address interpersonal relationships. For example, during the interviews, students behaved differently depending on who they interviewed. The teaching assistant playing the CTO, for example, had the impression that the students were quite aggressive with him. An attitude he attributed to them seeing him as one of theirs. The assistant playing the CEO, on the other hand, had the impression that the students who interviewed him were very polite, almost shy. This is an aspect we could add in the future.

The course ended with an outdoor farewell party in which most of the guest speakers were present and the students could talk about their career. This party was necessary to end the course in an adequate way. The stress and the emotions shared during the course had to be relieved through a social event. This was very enjoyable.

\section{Academic knowledge}

Our goals for the course were to provide an integrated view of business and IT aspects as well as to provide a context in which students could place the functional knowledge they learned during their studies. However, the course presented additional material 
which was not covered in the rest of the curriculum. For example, the structure of the main business processes (product sourcing, development, manufacturing), and enterprise modeling techniques are not taught elsewhere in our CS and SWE curriculum. We found during the exam that these concepts could be grasped in more depth. More specifically, the course goal was to give the students a feel for real work in organizations and some concrete knowledge on key business, RE and implementation concepts. The second aspect was not as successful as expected. Our plan is to address this issue by asking students to read research papers on some of these concepts and by offering quizzes more systematically.

\section{Effect on the teaching team}

As can be expected from an active, experiential course, it had a substantial and lasting effect on our research and our way of working. The course was developed collaboratively among the professor and teaching assistants. Most of the lectures were given by the professor. However, each TA had to give one lecture related to their research topic. This presentation was co-developed with the professor. In addition, after each course, we had a team debriefing to discuss the course contents. In these debriefings - which sometimes were quite long - we uncovered issues on which we did not agree. We also reinforced our understanding on what we agreed upon. As an end result, this helped us to publish significantly more of our research while giving the course, compared to previous years. When we gave the course, it also coincided with our decision to give up on independent offices and to work all together in a common open office, further improving our collaboration and research.

The students, too, became far more active than in traditional courses. They figured that since during the whole course we kept challenging them on their way of working together, that they could do the same to us. They actively challenged our way of working as a teaching team and demanded that we do the same. For example, at the last session of the course, we asked each student team to present what they learned during the course. When they were done, they asked us to do the same. These were wise remarks and we improved our working style significantly with the help of the students.

\section{Relationship with the workplace problems}

The course pedagogy addresses the workplace problems in Table 1 in the following way:
- The problems definition given to students is partial and unclear (row 1).

- Very few hints are given on how to approach the problems and the rules of the business game are discovered as the game unfolds (row 2).

- When students' teams present their work or verify its validity, these are often rejected by the teaching team playing the role of management (row 3).

- The scope of problems given to the student is totally unclear (row 4).

- The course is designed so that students have to work in teams to play the game and solve the problems (row 5).

- When students interview the teaching team as part of the game, the Interviewees give partial and potentially conflicting information (row 6).

- The methods to solve the problems are discovered by the student after the experience, during the debriefing sessions and theory is given only after these debriefings (row 7).

- Student teams are unstable because students are not required to attend the course. They have difficulty being accountable (row 8).

- The problem statement in the RE module changes from defining requirements to providing business value to customers in order to convince the main investor (row 9).

- Most documentation is given in verbal form through questions and answer during the experience. Very little written documentation is given. No textbook is used (row 10).

The following testimonial by one of the students who is finishing her Master's degree in the industry makes a nice link with Table 1:

\footnotetext{
In the course, it was also not always clear what was expected from us, which is unusual in an environment where our minds are shaped to solve a given problem. This was very uncomfortable and was perceived as a lack of organization. Now that I'm in a company, I realize how ill-defined and unclear are the problems and the goals and now understand why we had to go through this during the course. The situation is still uncomfortable in the real world, but at least I'm confident that tools exist to help me clarify things and plan to use them in the next steps of my project.
}

\section{Related Work}

The participants in a 2004 panel on RE education at the $12^{\text {th }}$ RE conference discussed the need to give students RE experience and the wicked problem issues. They also mentioned several courses that used experiential techniques. However, we were not able to find publications about these courses. 
Some publications about courses with active pedagogy were published at the REET 2005 workshop, e.g. [6] and [11]. [5] describes an immersive RE course that uses an IT simulated environment. They mention that the course was given in the past with a TA based simulation but that this was too costly, hence the move to IT based simulation. Business games and computer based simulation are also widely used in business education, e.g. for supply chain management [12].

It is worth noting that our course used human simulation and much debriefing effort to avoid the closed nature of computer based simulations.

\section{Conclusions and Future Work}

In this paper we have described an active experiential RE course and its underlying theory. The course was designed with two major objectives in mind: (1) to ease the transition of students into the workplace (2) to give students an understanding of Enterprise Architecture issues, i.e. business and IT alignment, RE, BPM and SOA development.

The current version of the course provides a platform to which we can add advanced experiential learning issues such as accommodation, apprehension and comprehension. We could do more to consciously integrate the zone of proximal development concept and particularly to expand each student's zone of proximal development in the encouragement metaphorical and analogic thinking and other creative mechanisms including .John-Steiner's cognitive pluralism [9].

We could add specific sessions on conflict management as well as ethics [1]. A formal evaluation by external experts in pedagogy can be a good leverage for the improvement of the course. A link with Bloom's taxonomy of educational objectives can also shed light on improvement opportunities. Finally, an independent evaluation of the impact of the course on students' experiences in industry, after graduation, beyond the anecdotal testimonial we have included above can lead to useful insights.

\section{References}

[1] Berenbach, B., "A Hole in the Curriculum”, Proc. 1st International Workshop on Requirements Engineering Education and Training (REET 2005), Sorbonne, Paris, France, August 30, 2005.

[2] Beyer H. and Holtzblatt K., Contextual Design: A Customer-Centered Approach to System Designs, Morgan Kaufmann, 1997.

[3] Checkland, P.and Holwell, S., Information, Systems and Information Systems - making sense of the field. Wiley, Chichester, UK, 1998.
[4] Cook, J. “An Interview with Barry Boehm”

ICE2000 Windows on the World ezine Issue2, 2000.

http://www.ul.ie/\%7Eicse2000/wow/issue2/barry_boehm_int erview.htm. Accessed May 21, 2005.

[5] Cybulski, J., Parker, C. and Segrave, S. (2006): "Using constructivist experiential simulations in RE education", in Didar Zowghi \& Lemai Nguyen (eds), Proc. of the 11th Australian Workshop on Requirements Engineering, pp. 110, University of South Australia, South Australia.

[6] Damian, D., Al-Ani, B., Cubranic, D. and Robles, L., "Teaching Requirements Engineering in Global Software Development: A report on a three-University collaboration”, Proc. 1st International Workshop on Requirements Engineering Education and Training (REET 2005), Sorbonne, Paris, France, August 30, 2005.

[7] Gause, D.C. and Weinberg, G.M., Exploring Requirements: Quality BEFORE Design, Dorste House, New York, 1989

[8] Gause D.C., "Making the case for the soft in Software Engineering: What does it really take to be prepared for the RE world ahead?” Keynote address, (Abstract) Requirements Engineering Workshop on Education and Training (REET 2005), Sorbonne, Paris, France, August 30, 2005.

[9] John-Steiner, V., "Cognitive Pluralism: A Sociocultural Appproach", Mind, Culture and Activity. Volume 2, No. 1, Winter 1995 1074-9039/95/2-11

[10] Kolb, D.A., Experiential Learning: Experience as the Source of Learning and Development, Prentice Hall, Englewood Cliffs, N.J. 1984.

[11] Madhavji, N.H. and Miller, J., "Investigation-based Requirements Engineering Education”, Proc. 1st International Workshop on Requirements Engineering Education and Training (REET 2005), Sorbonne, Paris, France, August 30, 2005

[12] MIT Forum for Supply Chain Innovation (2007). http://beergame.mit.edu/, accessed March 2007.

[13] Shum, S. J. Buckingham, MacLean, A., Bellotti, V.M. E., Hammond, N.V., "Graphical Argumentation and Design Cognition”, Human-Computer Interaction, v.12 n.3, 1997.

[14] Wegmann, A. "Theory and practice behind the course designing enterprise-wide IT systems”, IEEE Transactions on Education, 47 (4), 2004, 490 - 496.

[15] Wegmann, A., Regev, G., Rychkova, I., Lê, L-S, De La Cruz, J.D. and Julia, P., "Business-IT Alignment with SEAM for Enterprise Architecture", in Proc. 11th IEEE International EDOC Conference (EDOC 2007), Annapolis, Maryland, October 2007.

[16] Wegmann, A., Regev G., De la Cruz, J.D., Lê L-S and Rychkova I., "Teaching Enterprise and Service-Oriented Architecture in Practice”, Enterprise Architecture 10:4, 2007. [17] Weinberg, G. M. and Weinberg, D., General Principles of Systems Design. Dorset House. New York, 1988. 